\title{
Projeto de Assentamento Maisa: Conflito entre os Saberes Técnico e Popular no Processo de Planejamento Físico-Espacial do Seu Habitat
}

\author{
CERQUEIRA, Maria Cândida Teixeira ${ }^{1}$ \\ GERAH/PPGAU/UFRN, Natal, RN, Brasil.mcandidac@gmail.com
}

\begin{abstract}
Resumo
Como o arquiteto e urbanista pode assimilar conhecimentos e aprimorar sua prática profissional a partir da vivência de situações em conflito existente entre o seu saber técnico e o saber popular no mundo rural? Este artigo relata o envolvimento deste profissional no planejamento e concepção do espaço dos habitats do assentamento Maisa (19.702 ha), remanescente de grande empresa fruticultora do RN. Corresponde a uma experiência pioneira no país, visto que pela primeira vez, uma instituição de assessoria técnica (AESCA) a movimento social (MST) contrata, de maneira legalizada - com aval do Estado, através do INCRA - profissional da arquitetura e urbanismo, introduzindo novos saberes. Assim, durante o ano de 2005, através de metodologia participativa, a equipe técnica, lideranças e assentados, coordenados pelo MST, conceberam 0 projeto dos habitats (denominados agrovilas pelo INCRA) Pomar, Apodi, Real e Montana. Foram experienciados conflitos quanto a: localização dos habitats; dimensão dos lotes de moradia; modelo da habitação; modo de construção (mutirão ou contratação de empreiteiras). Apreende-se que as decisões finais devem ser fruto da avaliação coletiva dos limites entre o saber popular e as necessidades técnicas, entendendo os momentos de ruptura e de dominação, para deles tirar partido.
\end{abstract}

Palavras-Chave: Planejamento físico-espacial, Habitat, Conflitos saber técnico x popular

\begin{abstract}
How can the architect and urbanist assimilate knowledge and improve his professional practice from the situations of conflict between the technical and the popular learning in rural areas? This article relates the involvement of a professional in planning and conception of the habitat space at Maisa settlement (19,702 ha), remaining of a large fruit company in $\mathrm{RN}$. It represents a pioneering experience in the country because for the first time - by State guarantee, through INCRA -, a technical assistance institution (AESCA) for social movement (MST) legally hires a professional in architect and urbanism for this purpose in order to introduce new knowledge. Thus, in 2005, through participatory methodology, the technical team, leaders and settlers, coordinated by the MST, conceived the project of the habitats (denominated agrovilas by INCRA) Pomar, Apodi, Real and Montana. We experienced conflicts of various natures: placement of habitats; size of the living space; housing model; construction mode (either together or hired by the contractors). From that it has been learned that the final decisions must be a result of the collective evaluation of the limits between popular knowledge and technical needs by understanding both the ruptures and domination moments and taking advantage of them as well.
\end{abstract}

Key-words: Planning process, habitat, technical $\mathrm{x}$ popular knowledge conflicts. 


\section{Introdução}

$\mathrm{Na}$ concepção e organização de seus espaços físicos de moradia o ser humano procura imprimir características próprias de sua cultura, que são adquiridas e acumuladas no decorrer de suas experiências já vivenciadas. A maneira como a população ocupa a terra, o seu tempo de permanência, o tipo de material utilizado para a construção de seus abrigos, etc., são manifestações recorrentes não somente das condições materiais mas, também, do modo de vida onde estão inseridos. É a existência do ser humano, com suas características próprias, que gera a concepção de uma identidade em seu habitat, este entendido como o local destinado à moradia de sua população: lotes de moradia, área de equipamentos comunitários e arruamento (BORGES, 2001).

Esta constatação se faz mais perceptível nos aglomerados humanos onde ocorre a participação direta dos seus usuários na criação e organização do seu espaço físico, os quais, na maioria das vezes, não são detentores do conhecimento técnico necessário para desempenhar tal atividade.

Em outras situações, esse procedimento é caracterizado pela interação entre os profissionais detentores de conhecimento específico para tal atividade - os arquitetos urbanistas - e a população usuária, em grande parte leiga no assunto. Neste processo muitos conflitos são desencadeados entre o saber técnico e o popular até alcançar a concepção de um espaço de moradia que, teoricamente, melhor se adapte aos anseios de seus usuários. É o que muitas vezes ocorre, atualmente, no planejamento do espaço físico do habitat dos assentamentos de "reforma agrária".

Depois de desapropriado, o imóvel rural é transferido para os trabalhadores que pleiteavam seu uso e se transforma num Projeto de Assentamento (PA). A partir deste momento da-se início ao seu processo de implantação, com a fixação das famílias e a criação de condições ideais para o seu desenvolvimento. Dentre as várias ações realizadas, tem-se o planejamento do habitat. Na maioria das vezes, esta atividade é conduzida pela equipe técnica do Instituto Nacional de Colonização e Reforma Agrária (INCRA) ou das Entidades que prestam assistência técnica aos assentados - os "teóricos" detentores do conhecimento técnico -, havendo a participação da comunidade interessada. Através de reuniões ou oficinas, são travadas discussões para se chegar a uma proposta que melhor se adeque às necessidades dos assentados. São nesses momentos que ocorrem os conflitos, confrontando-se o saber técnico dos profissionais envolvidos e o popular dos assentados.

Dentro desta dinâmica, o presente estudo procura descrever como se dão esses conflitos entre o saber popular dos assentados e o técnico dos profissionais arquitetos urbanistas no momento da concepção e planejamento do espaço físico de habitats dos assentamentos "de reforma agrária". Assim, procura-se perceber como o profissional arquiteto urbanista pode refletir sobre esses conflitos, tirar partido, e assim desempenhar melhor sua função.

Para tanto, tem-se, como pano de fundo o assentamento Maisa, no município de Mossoró, estado do Rio Grande do Norte (RN). Aqui realizou-se a primeira experiência em planejamento físico-ambiental de assentamentos "de reforma agrária" desenvolvida por uma profissional da Arquitetura e Urbanismo contratada especificamente por uma Instituição, a AESCA (Associação Estadual de Cooperação Agrícola do Estado do Rio Grande do Norte), que presta assessoria técnica rural ao Movimento dos Trabalhadores Rurais Sem Terra (MST) no RN para compor seu quadro técncio e desenvolver tal função. Esta experiência foi desenvolvida pela presente autora durante o decorrer de todo 0 ano de 2005. Na Maisa foram assentadas 1.150 famílias, divididas em três movimentos sociais: FETARN (Federação Estadual dos Trabalhadores da Agricultura do Rio Grande do Norte); MST e APAMA (Associação dos Produtores da Antiga Maisa). Ao MST coube 400 famílias, que foram subdivididas em quatro agrovilas: Pomar, Apodi, Real e Montana. Maisa representa experiência única no estado 
relacionada ao planejamento físico-ambiental de assentamentos "de reforma agrária", e o MST como a entidade pioneira em tal procedimento.

Assim, o desenvolvimento deste trabalho iniciou-se pela realização de uma revisão teórica sobre os tópicos relacionados ao tema, procurando adquirir mais conhecimentos sobre as questões trabalhadas. Em seguida, buscouse analisar a experiência verídica que foi desenvolvida no assentamento Maisa. Após a descrição desta vivência, buscou-se entender os principais conflitos ocorridos entre o saber popular dos assentados e o técnico do arquiteto urbanista, principalmente. Por fim, chegou-se nas considerações possíveis.

\subsection{Assentamentos "de Reforma Agrária"}

Segundo dados do Instituto Brasileiro de Geografia e Estatística (IBGE) $81,25 \%$ da população brasileira reside em áreas consideradas urbanas, enquanto que $18,75 \%$ vive no meio rural. Em contrapartida, a maior parte das nossas terras pode ser classificada como de origem rural, sendo caracterizadas pela dispersão populacional, que em nosso país ainda é agravada pela concentração fundiária, herança do tipo de colonização que aqui foi implementada.

Apesar desta realidade, contudo, ocorre a expansão nas ultimas décadas, no meio rural, de um modelo recente de habitat humano. São os denominados assentamentos de "reforma agrária", e dentre estes estão os provenientes do MST.

O MST se caracteriza como um movimento social de massa que, organizado política e ideologicamente, procura transformar sua própria condição social, lutando pelos seus direitos e sonhos. Atua, de forma mais efetiva, no meio rural através de ocupações de terras consideradas improdutivas, promovendo manifestações, pressionando os detentores do poder e forçando a ação do governo. É um dos movimentos sociais que mais operam em nossa sociedade. Devido a essa postura, o MST pode ser considerado como uma das molas propulsoras em relação à criação de assentamentos "de reforma agrária" em nosso país, sendo um dos principais agentes que induzem os responsáveis por esta prática - o Instituto Nacional de Colonização e Reforma Agrária (INCRA) (FERNANDES, 1996).

Os assentamentos coordenados pelo MST são espaços rurais constituídos, na maioria das vezes, por uma área destinada à produção agrícola (que pode ser individual ou coletiva, ou ambas); área de equipamentos remanescentes; área de reserva legal (correspondendo a 20\% da área total); área de preservação permanente (margem de rios, riachos, açude e topografias com bastante declives) e o habitat, este entendido como o local destinado à moradia de sua população: lotes de moradia, área de equipamentos comunitários, arruamento (BORGES, 2001).

Estes assentamentos podem ser classificados, de acordo com a configuração espacial, como concentrado, disperso ou misto. Na primeira configuração as moradias e alguns serviços coletivos estão reunidos num mesmo espaço, separados da área de trabalho (comumente denominado agrovila). A segunda situação se caracteriza por apresentar as moradias localizadas no próprio lote de trabalho. E a última mescla elementos das duas primeiras (BORGES, 2001).

\subsection{Planejamento Físico-Espacial dos Assentamentos "de Reforma Agrária"}

Para realizar, de modo adequado e satisfatório, as atividades de planejamento dos espaços físicos, vê-se necessário a presença de um profissional arquiteto urbanista. Tal profissão é regulamentada pela lei 12.378/2010, tendo como competência e atribuição o exercício de atividades, como supervisão, orientação técnica, coordenação, planejamento, projetos, especificações, direção e execução de obras, ensino, assessoria, consultoria, vistoria, perícia e avaliação, as quais estiverem relacionadas a edificações, conjuntos arquitetônicos e monumentos, arquitetura paisagística e de interiores, urbanismo, planejamento físico, urbano e regional.

A partir das últimas décadas vem-se 
percebendo um aumento da participação popular nos processos de planejamento (DEL RIO, 1990). Nos países subdesenvolvidos se nota, contudo, um outro processo que se sucede de modo frequente. De uma maneira não oficial, ocorrem intervenções onde a própria população é quem dita as normas, estabelecendo como o seu espaço de moradia deve ser organizado e estruturado. É o que acontece nos assentamentos espontâneos favelas; regiões periféricas de baixa renda; assentamentos concebidos por movimentos sociais (MST; Movimento dos Sem Teto). Nessas situações verifica-se o estabelecimento de uma relação mais íntima entre o espaço e a identidade cultural de seus ocupantes. Esses transformam o local de moradia, estruturando-o e qualificando-o de acordo com seus conhecimentos adquiridos ao longo de suas histórias individuais e coletivas. Esses conhecimentos findam por refletir as heranças culturais daqueles indivíduos, seus reais anseios e necessidades. Apesar de não se configurar, na grande maioria dos casos, como um exemplo do uso da técnica e do conhecimento cientifico adequado, finda por representar, para a população usuária, a melhor opção, que atende de forma apropriada as suas necessidades.

Os habitats dos assentamentos "de reforma agrária" provenientes do MST são exemplos dessas práticas. Quando representam um espaço físico estruturado, primordialmente, pela própria população usuária, fica clara a relação que acontece entre os elementos culturais pertencentes aos moradores e seu espaço físico de moradia.

No entanto, em grande parte dos casos o que acontece é um confronto entre os técnicos detentores do conhecimento teórico, pertencentes à equipe técnica do INCRA ou das Instituições que prestam assistência técnica, e a comunidade - na maior parte dos casos leiga no assunto - que irá usufruir este espaço. Até se chegar a uma proposta que realmente atenda as necessidades dos moradores, estando de acordo com seus sonhos e anseios, ocorrem muitos conflitos se saberes, entendimentos e até mesmo de interesses. É o que pode ser observado na experiência de planejamento físico-ambiental do habitat do assentamento Maisa, relatada a seguir.

\section{Maisa: Experiência em Assistência Técnica para o Planejamento Físico- Ambiental de Assentamento "de Reforma Agrária" Coordenado Pelo MST}

\subsection{O Convênio}

A partir de Novembro de 2004, no estado do $\mathrm{RN}$, o INCRA e o Serviço Brasileiro de Apoio às Micro e Pequenas Empresas (SEBRAE) celebraram um convênio para subsidiar por dois anos a assistência técnica rural no Estado. Por meio deste, o MST torna-se a primeira entidade do meio rural, no $\mathrm{RN}$, a contratar um profissional da Arquitetura e Urbanismo para compor o quadro da equipe técnica da Instituição que presta assessoria técnica aos seus assentamentos - AESCA - para trabalhar especificamente com a questão do planejamento físico-ambiental nos assentamentos.

No primeiro momento este convênio não permitia, em seu quadro técnico, a contratação do arquiteto urbanista. Porém, o MST, buscando ampliar suas ações na área do planejamento e execução dos habitats de seus assentamentos, que vinha sendo há algum tempo assessoradas pelo Grupo de Estudo de Reforma Agrária e Habitat (GERAH) do Departamento de Arquitetura e Urbanismo (DARQ) da Universidade Federal do Rio Grande do Norte (UFRN), pressionou os executantes do convênio e exigiu que fosse admitida a contratação de tal profissional. E assim foi feito.

\subsection{A demanda existente}

No início de 2005 o MST-RN possuía uma demanda de 10 áreas que necessitavam de planejamento físico-ambiental em seus habitats. Constituíam exemplares onde se residia sem nenhuma condição de habitabilidade. A prioridade inicial foi dada ao assentamento Maisa, em Mossoró, na região oeste do estado. $\mathrm{Na}$ época foi denominado "Eldorado dos Carajás II". Contudo, com o passar do tempo, 
os assentados o "rebatizaram" de Maisa (Figura 01).

\subsection{A área escolhida}

Figura 01: Visão geral do PA Maisa.

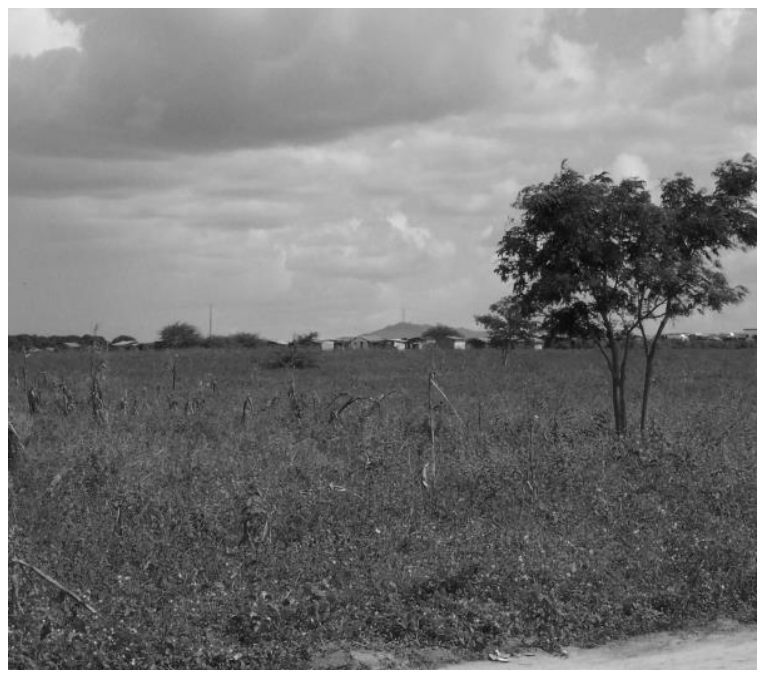

Figura 02: Mapa do Assentamento Maisa: divisão por movimento social.

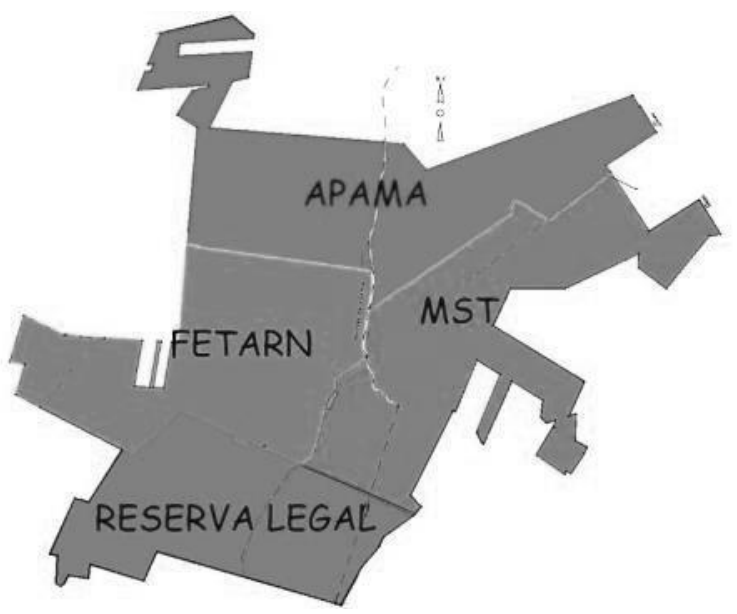

A área corresponde à antiga Fazenda MAISA Mossoró Agroindustrial Sociedade Anônima antigo símbolo de poder da região, grande produtora de caju e melão, transformou-se numa área de interesses e conflitos diversos.

Depois de falida, a área foi ocupada pelo MST e FETARN, onde famílias de trabalhadores rurais permaneceram acampadas por certo tempo, como maneira de reivindicar a desapropriação da área que ora se encontrava improdutiva. Durante o ano de 2002, seus 19.702 hectares foram desapropriados, transformando-se no assentamento Maisa (Figura 02). Esse foi um processo repleto de conflitos, das mais variadas naturezas.

Assentou-se 1.150 famílias, divididas em 3 movimentos sociais: FETARN, MST E APAMA. Ao MST coube 400 famílias, para as quais foram destinados os 6.030 hectares que se encontravam mais próximo à Mossoró, tendo como principal acesso a rodovia BR - 304 que liga esta cidade à Fortaleza, capital do Ceará. A área pertencente ao MST apresenta um relevo caracteristicamente plano, com vegetação nativa e resquícios das culturas que eram exploradas na época da antiga fazenda, englobando grande parte dos pomares de acerola e caju. Porém, é uma região com carência de água. Foi contemplada com parte da infraestrutura remanescente: casa sede da fazenda; galpões de armazenamento; pequenas edificações; estradas vicinais; poços d'água; estrutura para energia elétrica; dentre outros.

\section{A Metodologia para a Elaboração da Proposta de Habitat}

A proposta consistia em desenvolver o planejamento e a organização espacial do habitat (lotes de moradia, área de equipamentos comunitários e arruamento) da área destinada as 400 famílias do MST, chegando à construção das habitações. A metodologia empregada para tal buscou a participação da população beneficiada em todas as etapas do processo, tendo como objetivo final a construção das habitações em regime de mutirão autogerido, onde os moradores iriam erguer suas habitações e gerenciar o processo. Assim, as etapas seriam: reuniões; aplicação de questionários; realização de oficinas sobre habitação; coleta de dados físicos; compilação dos dados; concepção do projeto; discussão da proposta; definição da proposta final. Após seria discutido o modo de construção $e$, na sequencia, sua efetiva execução. Abaixo, serão descritas essas etapas.

Havia todo um respaldo das lideranças do MST para com a metodologia, que era condizente com sua ideologia. À frente da condução do processo, além das lideranças locais do MST e os coordenadores de base do assentamento, 
estavam os técnicos da assistência técnica da AESCA: arquiteta, assistente social, agrônomo e técnico agrícola.

\section{- Reuniões}

O processo iniciou através da realização de reuniões, que tinham como objetivo explicar a metodologia empregada na condução das atividades. Estas reuniões aconteciam nos próprios locais onde as famílias estavam acampadas, contando com a participação da base assentada e das lideranças do MST responsáveis pela área.

\section{- Aplicação de questionários}

$\mathrm{Na}$ sequencia, deu-se início à coleta de informação sobre a população moradora a partir da aplicação de questionários. Para tanto, utilizou-se dois tipos: um individual por família e um coletivo por núcleo de família (conjunto de 10 famílias que reflete a organização social do MST). O primeiro questionário estava dividido em três partes: dados pessoais; situação anterior, e situação atual. Objetivava traçar um perfil social e econômico das famílias, bem como compreender o seu histórico e a situação atual em relação à moradia. Já o segundo buscava verificar como as famílias ansiavam o habitat, nos aspectos relacionados à infraestrutura e aos equipamentos coletivos; modo de produção; organização e tipo de habitação. Foi feito um treinamento com as lideranças do MST e os coordenadores da base para auxiliar os técnicos na aplicação dos questionários.

\section{- Oficinas sobre habitação}

Para complementar as informações sobre o tipo de habitação que os assentados desejavam, realizaram-se "oficinas de habitação". Consistiam em reuniões, onde trabalhando em grupos, através de discussões e desenhos, os assentados expressavam os seus desejos e necessidades em relação ao tipo de moradia pleiteada. Como aconteceu nas reuniões iniciais, essas duas etapas acima descritas eram realizadas nos locais onde as famílias estavam acampadas.

\section{- Coleta de dados físicos}

Para coleta dos dados físicos foram percorridos os principais pontos do assentamento, especialmente as áreas onde os assentados propunham que fossem localizados os habitats. Assim, através da observação in loco, registros fotográficos, mapas e orientações de outros profissionais - engenheiros agrônomos, engenheiros civis, técnicos agrícolas - foram coletadas as informações físicas necessárias.

Nestas etapas iniciais existiu muita dificuldade no trabalho. As distâncias que deviam ser percorridas eram demasiadas e não existia meio de transporte regular disponível, por parte da AESCA, para o deslocamento dos técnicos. Além disso, o contingente de famílias a serem entrevistadas, bem como para participar das oficinas, também era grandioso, sendo incompatível com 0 número de técnicos disponíveis para o trabalho. Este número de técnicos, no decorrer do processo, foi diminuindo, restando, ao final, somente a arquiteta.

\section{- Concepção do projeto: agrovila, habitações e locais para os futuros equipamentos coletivos.}

Após o período de coleta de informações, que durou aproximadamente três meses, partiu-se para a compilação dos dados e a elaboração da proposta para organização espacial do habitat da área. Desse modo, foi elaborado o projeto do habitat como um todo; o projeto da habitação; e a indicação do local dos futuros equipamentos coletivos (praça; campo de futebol; área de lazer; escola; posto de saúde; igreja; etc.).

Optou-se pelo habitat concentrado (agrovila). Assim, as 400 famílias foram divididas em quatro agrovilas: Pomar (130 famílias); Apodi (100 famílias); Real (70 famílias) e Montana (100 famílias). Suas localizações ficaram nas proximidades das áreas em que as famílias estavam acampadas, assumindo também suas denominações. A primeira agrovila, com o maior contingente populacional, encontrava-se mais próximo da via de acesso para os centros urbanos e de um dos pomares de acerola 
remanescente da produção da antiga fazenda (Figura 03). A agrovila Apodi, por imposição dos assentados, foi locada próxima a uns galpões de armazenamento remanescentes (Figura 04). A agrovila Real foi a que ficou mais para o interior do assentamento, estando afastada dos acessos para os centros urbanos, contudo, nas proximidades dos lotes de trabalho individuais (Figura 05). Já a agrovila Montana ficou no terreno mais plano, próximo a uns galpões de armazenamento remanescentes e de um pomar de acerola ainda produtivo (Figura 06).

O processo de distribuição das famílias entre as agrovilas ficou por conta da comunidade e das lideranças do MST, que já possuíam critérios próprios a serem levados em consideração.

O tamanho do lote de moradia proposto foi o $40 \times 70 \mathrm{~m}$, padronizado com o mesmo formato e dimensão, mas sendo utilizado de maneiras diferentes. Tamanho suficiente para se habitar e praticar agricultura de subsistência pela família. A distribuição do lote de moradia se deu em conjuntos compostos por 10 lotes, correspondendo a um núcleo de família (unidade na qual o MST organiza socialmente as famílias assentadas). Para sua disposição foi levado em consideração critérios como topografia do terreno, posição em relação à insolação, preocupação com uma faixa de segurança em relação as vias de acesso para evitar acidentes, barulhos, dentre outros. Ao redor de cada agrovila foi destinada uma área para produção agrícola coletiva de subsistência, denominada área de segurança alimentar.

Figura 03: Implantação da Agrovila Pomar.

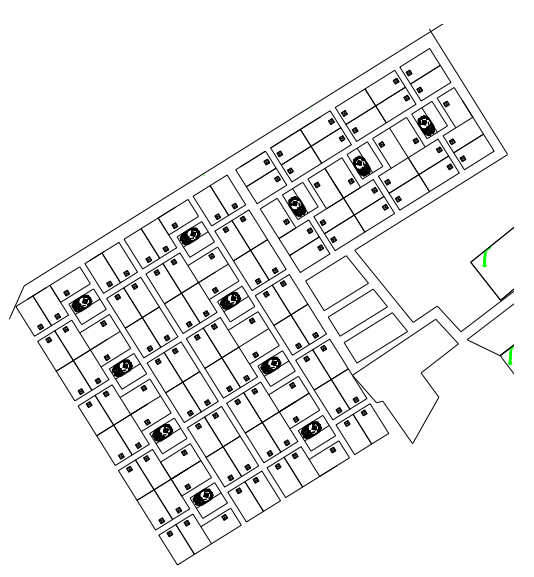

Figura 04: Implantação da Agrovila Apodi.

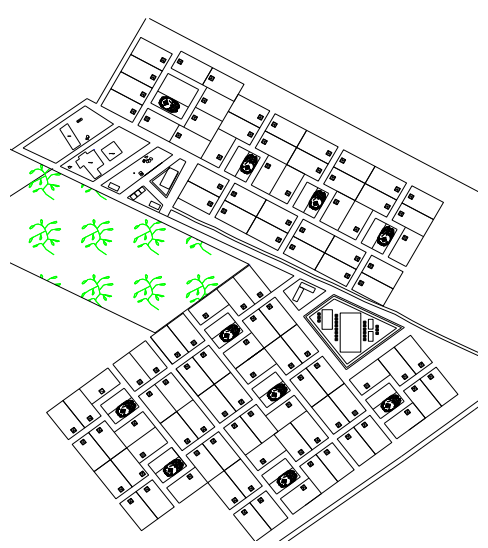

Figura 05: Implantação da agrovila real.

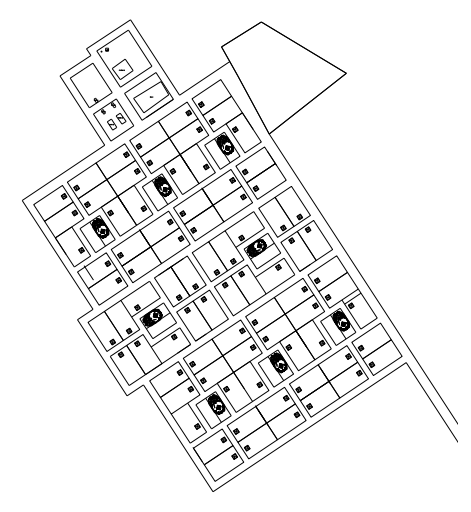

Figura 06: Implantação da Agrovila Montana.

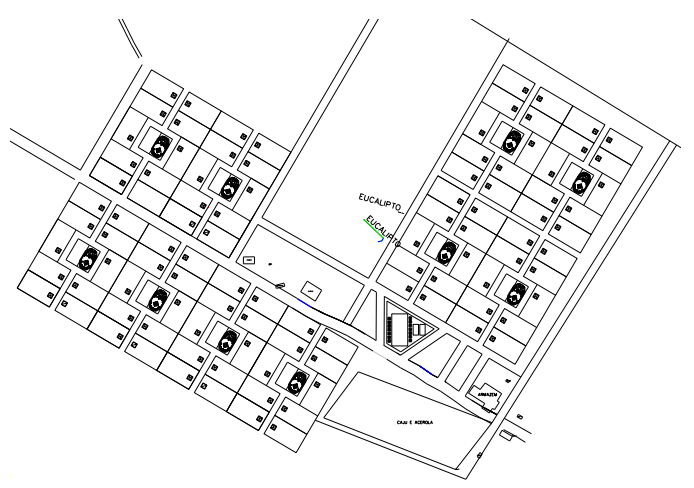

Em relação à infraestrutura básica houve a preocupação de que todas as casas das agrovilas fossem atendidas por energia elétrica, água e saneamento básico, sendo estes elementos também critérios preponderantes para escolha do local para implantação das habitações, deixando-as 0 mais próximo possível entre si, para baratear o custo com os investimentos. Além disso, teve-se a 
preocupação com a questão do lixo e da arborização.

Para a escolha do modelo da habitação houve a preocupação com uma concepção espacial que privilegiasse 0 conforto, bem estar e privacidade, levando em consideração aspectos de conforto ambiental e forma, tudo condizente ao valor dos recursos disponíveis para a sua execução: cinco mil reais. Optou-se por um modelo único e padronizado para todas as 400 famílias assentadas (Figuras 07 e 08).

Figura 07: Planta baixa da habitação proposta.

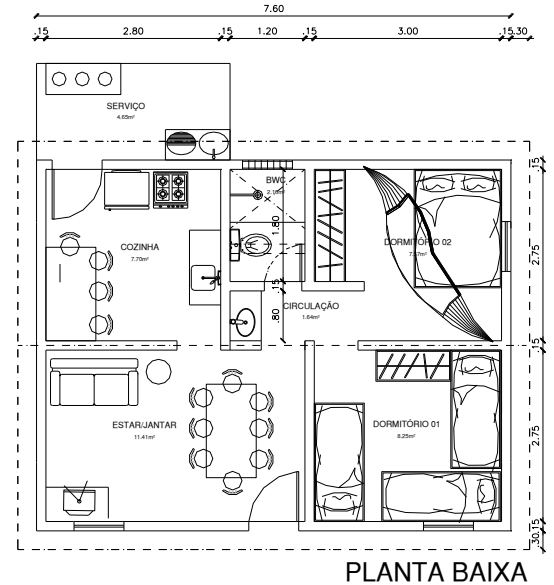

Figura 08: Fachada principal da habitação proposta

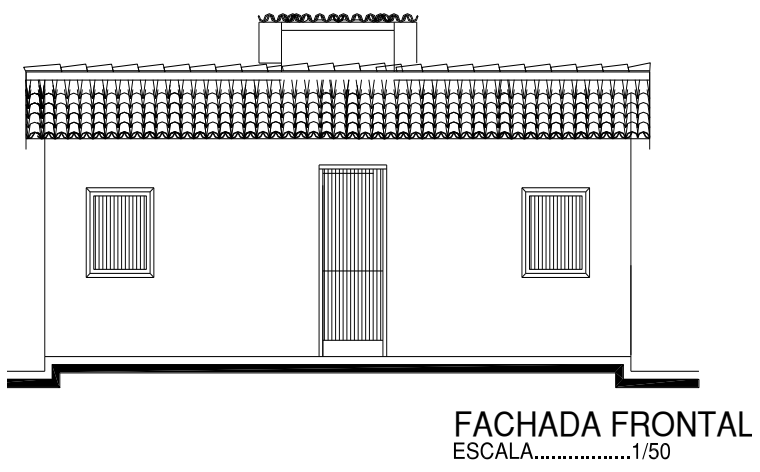

\section{- Discussão da proposta}

Com a proposta em mãos, partiu-se para as discussões com as lideranças do MST, os coordenadores do assentamento e sua base. A partir de então houve um aumento no nível de conflitos. Por tudo o que aquela área representava, havia muitos interesses em jogo: político, econômico, social, etc. $E$ já não bastasse a pressão dos assentados, começou as cobranças das autoridades do INCRA para que a execução do projeto fosse concretizada o mais rápido possível, pois até o final de 2005 o Presidente da República, cumprindo promessa feita à época da desapropriação, viria visitar o assentamento e verificar como estava o seu desenvolvimento. Isso prejudicou muito as discussões, fazendo com que etapas do processo não fossem desenvolvidas no tempo devido, tendo sido aceleradas.

\section{- Definição da proposta}

Assim, após muitas reuniões, discussões e uma série de conflitos das mais variadas naturezas, chegou-se a proposta definitiva. Esta não fugiu do que tinha sido proposto inicialmente, como foi descrito anteriormente. Teve a interferência dos assentados em todas as etapas, devendo ser considerada uma construção coletiva.

\section{- A execução da proposta do habitat}

Depois de aprovada a proposta, a etapa seguinte foi a preparação para sua execução. $A$ marcação da implantação das agrovilas ficou sobre a responsabilidade da equipe de topografia do INCRA. Concomitante, partiu-se para a definição, planejamento e organização do modo de construção das habitações.

\section{- Definição do modo de construção}

Até o momento da finalização da proposta para o habitat, estava tudo acertado que o modo de construção das habitações seria por regime de mutirão autogerido, onde cada família iria construir sua própria moradia. Por se tratar de um objeto de grande montante -1.150 casas ao todo; destas, 400 do MST -, havia preocupação para com o planejamento de sua construção, buscando minimizar os eventuais problemas. Existiu um contato com a FIERN (Federação das Indústrias do Rio Grande do Norte) para que ela pudesse fornecer o apoio técnico ao processo de mutirão, por meio da disponibilidade de professores para qualificar a mão de obra que iria dele participar. Dos três movimentos sociais envolvidos, o MST foi o único que se mostrou favorável ao mutirão e ao apoio disponibilizado.

\section{- Mudanças de planos}


No entanto, às vésperas de iniciar o proceso de construção das habitações, com tudo acertado em ata, os assentados desistiram do mutirão autogerido e decidiram contratar construtoras para a execução das moradias, seguindo o mesmo caminho dos outros movimentos e rompendo com o sentido original proposto. Apenas um pequeno grupo de 35 famílias, da Agrovila Montana, persistiu com a idéia inicial do mutirão autogerido.

\section{- Desligamento das atividades}

A partir deste momento a autora se afastou do processo, dando por encerrada sua participação, pois havia se perdido o significado inicial planejado e para o qual até então havia se trabalhado.

\section{- Construção das casas}

Contudo, o processo não parou. O INCRA convocou uma força tarefa, trazendo servidores de outros estados para finalizar o processo. Assim, foram elaborados os projetos de infraestrutura (rede elétrica, estradas, abastecimento de água, dentre outros) e organizada uma licitação para definição das empresas que iriam construir as habitações. Logo após, iniciou-se o processo de construção.

\section{Os Conflitos}

Para se chegar ao projeto final proposto, anteriormente descrito, muitos foram os conflitos travados entre as partes envolvidas técnicos da assistência técnica (arquiteta), lideranças do MST e base assentada. Neste capítulo, busca-se destacar as principais decisões e analisá-las, com a intensão de melhor compreendê-las.

\section{A quantidade de agrovilas, sua localização} espacial e quantidade de famílias foi uma decisão bastante questionada, onde o embate entre o saber técnico e o popular foi bastante acirrado. Os assentados propunham três agrovilas, com igual número de famílias. Sua locação deveria ser próxima aos acessos principais, para facilitar a locomoção para os centros urbanos, como também perto da infraestrutura remanescente (especialmente dos antigos galpões de armazenamento) e dos pomares de acerola e caju que ainda se encontravam produtivos. Não mencionavam a preocupação com a distância que teriam que percorrer para os lotes de trabalho agrícola, que correspondem basicamente a toda a área do assentamento, e que seria cada vez maior, quanto menor fosse o número de agrovilas. Foi o que aconteceu com os acampados que iriam compor a agrovila Apodi. Eles só aceitavam a locação da agrovila ao lado dos galpões, onde já se encontravam acampados, justificando que estando ali seria mais fácil zelar por aquela infraestrutura, mesmo sendo avisados de que aquele terreno não era o mais propício para a construção das casas, devido sua topografia irregular, o que acarretaria aumento nos custos da obra.

No nosso entender seriam necessárias quatro agrovilas, com igual número de famílias, distribuídas no espaço físico de maneira o mais eqüidistante possível, para ocupar a área do assentamento como um todo e se evitar percorrer grandes distâncias do lote de moradia para a área de trabalho. Além disso, deveriam estar em terrenos planos e de fácil acesso à infraestrutura, ou que não dificultasse a chegada desta e nem a encarecesse.

Diante do impasse estabelecido, buscou-se elementos para compreendê-lo e, assim, chegar a uma alternativa que atendesse à comunidade de forma adequada. Assim, o fato de escolherem a locação da agrovila nas proximidades dos acessos principais ao meio urbano, bem como da infraestrutura remanescente, representava para os assentados a oportunidade de melhorar as condições de sua moradia e de vida, pois teriam perto de casa acesso para as cidades, onde estabelecem relações de trocas e serviços, além de procurar conservar a infraestrutura por eles conquistada de maneira tão penosa. Significava o rompimento com uma situação que há muito tempo vivenciavam: a falta de um local com ideais condições de moradia. Não se importavam com as longas caminhadas de casa para o local de trabalho porque isso já fazia parte do seu habitus, - fundamento objetivo de 
condutas regulares (BOURDIEU, 2004).

Assim, esses critérios foram levados em consideração na proposta. Contudo, conseguiuse demonstrar que a distribuição espacial da população num maior número de agrovilas promoveria a ocupação do assentamento como um todo, como facilitaria a produção agrícola. Em contrapartida, abriu-se mão da distribuição uniforme da população, ficando mais povoada a agrovila Pomar, que reunia todos os critérios acima descritos almejados pelos assentados.

Em relação à escolha de quem iria morar em cada agrovila, foi uma decisão que se achou por bem deixar por conta dos assentados e as lideranças do MST, por entender que se tratava de uma questão da organização social interna. No entato, percebeu-se que a base assentada, sempre submissa às decisões das lideranças do MST, rompeu com essa dinâmica ao exigir que o principal critério para a escolha fosse a quantidade de tempo que a família se encontrava acampada, e não os ditados pelas lideranças do Movimento. Neste processo, o MST representa os detentores do poder político, social e ideológico dentro do assentamento, dominando a massa assentada através da disciplina e do poder (FOUCAULT, 1987). Pela ordem, prescreviam o lugar de cada um dentro do tecido social que formava o assentamento. Ditavam os postulados, guiados pela ideologia do Movimento, que deveriam ser seguidos por todos. Quando a base assentada exige um critério elaborado por ela, rompe com essa submissão.

No que se diz respeito à definição do tamanho do lote de moradia também houve discordâncias entre as partes. Os assentados iniciaram as discussões com a proposta de $50 \times 100 \mathrm{~m}$, justificando ser uma dimensão ideal para habitar e produzir uma agricultura de subsistência. Entretanto, os técnicos não concordaram pois, por conhecimento de experiências anteriores, sabia-se que essa dimensão extrapolava o necessário para as atividades propstas, 0 que acarretaria em desperdício de área e/ou abandono dos lotes de trabalho. Recomendou-se o tamanho $30 \times 60 \mathrm{~m}$, que não foi aceito por julgarem ser pequeno.
Então, partiu-se para um meio termo, chegando-se ao valor de $40 \times 70 \mathrm{~m}$. Apesar de achar que essa dimensão não era a mais adequada para a organização espacial e que também poderia ocorrer o desperdício de área e/ou abandono dos lotes de trabalho, achou-se por bem concordar. Esse ato representava o querer daquela comunidade, a oportunidade de poder escolher algo que para eles era bastante significativo. Era o rompimento com uma situação na qual eles sempre representavam os submissos e agora estavam com 0 direito de escolha.

Em relação à configuração espacial dos lotes de moradia não ocorreram muitos conflitos. Os assentados apenas exigiram que os lotes fossem padronizados, com o mesmo formato, tamanho e metragem quadrada. No entender dos técnicos, deveria existir a diversidade, pelos menos, de formatos, buscando tornar o espaço mais interessante. No entanto, percebeu-se que, para os assentados, a padronização simbolizava a igualdade de direitos e de oportunidades. Portanto, foi aceita a padronização. A esta somou-se a preocupação com os critérios técnicos - topografia do terreno; posição em relação a insolação; faixa de segurança em relação as vias de acesso para evitar acidentes; dentre outros - apresentados pela assistência técnica e aceitos pelos assentados sem muito questionamentos. Assim, predominou o poder e a dominação do conhecimento técnico, que com os argumentos e explicações convenceu facilmente. Simboliza a dominação dos detentores do poder técnico e a submissão da base assentada.

Outro ponto de pouco conflito correspondeu à discussão sobre os lotes de trabalho, área de segurança alimentar, Infraestrutura (equipamentos coletivos, água, luz, saneamento, lixo, arborização) e Modelo da casa. No primeiro quesito a divergência foi em relação à preocupação com as distâncias que deveriam ser percorridas pelos assentados do lote de trabalho ao de moradia. Os assentados manifestavam não ter muita noção da dificuldade que seria para a futura produção agrícola do assentamento se os lotes de 
trabalho ficassem muito longe dos locais de moradia. Sua preocupação maior era que a moradia fosse acessível às vias que davam acesso aos centros urbanos. Contudo, demonstrando os valores numéricos que deveriam ser percorridos, através de simulações ilustrativas, apesar da resistência de alguns, a maioria deu-se por convencida e aceitou a proposta que procurava deixar os lotes de trabalho o mais próximo dos lotes de moradia.

O mesmo aconteceu com a proposta da área de segurança alimentar. Estava sendo proposto, pela assistência técnica, que ao redor da agrovila fosse destinada uma área coletiva para produção agrícola de subsistência. A princípio, muitos admitiram a não necessidade desta área. Contudo, após as discussões e explicações, aceitaram a proposta.

Em relação à infraestrutura necessária ao assentamento, os moradores se contentavam apenas com energia elétrica e água. Todavia, a assintência técnica ansiava que as moradias fossem atendidas, não apenas por esses dois elementos, mas por soluções para 0 saneamento básico, lixo e arborização, sendo estes critérios preponderantes para escolha do local para implantação das habitações, deixando-as o mais próximo possível, para baratear 0 custo dos investimentos em infraestrutura. De inicio os assentados se mostraram resistentes, achando não necessário esse aparato de cuidados. Mas, depois das explicações, acataram as propostas, sem demais questionamentos.

O mesmo processo ocorreu nas discussões sobre os modelos das habitações. A princípio diziam querer um modelo simples e de fácil execução, demonstrando pouca preocupação com a disposição dos ambientes, se obedeciam a uma lógica básica. Para demonstrar-Ihes a necessidade de uma distribuição espacial que privilegiasse 0 conforto, bem estar e privacidade, levando em consideração aspectos de conforto ambiental e estética, sem fugir do orçamento disponível, foram realizadas oficinas de desenho da habitação. Assim, os assentados compreenderam o que estava sendo exposto.
Mais uma vez sobressaiu a dominação do poder do conhecimento técnico em relação ao popular.

Contudo, o principal conflito ocorrido foi em relação ao modo de construção. Desde as primeiras discussões, a proposta consistia em construção por regime de mutirão com a participação das famílias assentadas, conceito defendido pelo MST. Contudo, às vésperas de iniciar a obra, a base assentada mudou de opinião e decidiu contratar Empreiteiras para executar as moradias, desprezando todo o processo que até então estava organizado.

Percebe-se, na verdade, que grande parte da base assentada não estava totalmente convencida da opção pelo o mutirão. Isso já tinha ficado claro nos momentos das discussões, quando se debatia a temática. Muitos se manifestavam dizendo não ser a favor do mutirão, pois eram agricultores e não pedreiros, e por isso não saberiam construir. Porém, as lideranças do MST intervinham, discursando para demonstrar a importância do mutirão. Para eles, além de melhorar a qualidade da construção, seria a possibilidade do assentado estar aprendendo um novo ofício e não gerando lucros para os donos das construtoras. A assistência técnica complementava, mostrando que o recurso disponibilizado para a construção era pouco $(R \$$ $5.000,00)$ e que não daria para contratar construtora, ou se desse, essa não executaria o serviço de maneira satisfatória. No mais, com o mutirão todo o dinheiro deveria ser investido na própria obra, o que significaria uma melhoria na qualidade da habitação, pois o poder de barganha dos assentados para a compra do material, pelo quantitativo existente, consistia imenso e se voltaria somente em benefício deles.

No entanto, estes argumentos não foram suficientes para convencê-los. Somando-se a isso, suspeita-se de influências externas, com interesses econômicos que o processo poderia proporcionar, sendo estes os prováveis manipuladores da base assentada. Têm-se noticias que donos de pequenas construtoras da região estavam sempre "rondando" o 
assentamento, visitando os assentados que detinham um poder maior de liderança entre a base. Contudo, apenas 35 famílias da agrovila Montana continuaram no propósito do mutirão e construíram suas habitações.

Observa-se que a mudança de opinião da base assentada em relação ao modo de construção simboliza um rompimento para com a dominação ideológica que as lideranças do MST exerciam. O Movimento representava o detentor do poder, e que por meio deste exercia o controle das relações sociais as quais os assentados estavam sujeitos. Entretanto, levase a crer que para esse rompimento a massa assentada também sofreu influências, sendo dominada por outro agente, porém externo ao processo e que provavelmente tinham algum interesse nesse rompimento, possivelmente econômico, devido ao montante de dinheiro envolvido. Mudou apenas o agente dominador, sendo a base assentada explorada da mesma maneira pelos detentores do poder, seja ele qual for.

\section{Considerações Finais}

O processo de planejamento físico-ambiental do habitat de uma área envolve uma série de variáveis, principalmente quando desenvolvido por meio da interação do saber técnico (arquitetos urbanistas) e do popular (comunidade usuária). Ocorrem vários conflitos, das mais diversas naturezas.

A experiência em planejamento físico-ambiental do habitat do Assentamento Maisa considerada a primeira experiência, no $\mathrm{RN}$, em planejamento físico-ambiental de assentamentos "reforma agrária" desenvolvida por um arquiteto urbanista, contratado por Instituição que presta assessoria técnica no meio rural, para desenvolver especificamente esta atividade - correspondeu a um desses casos.

A área já apresentava um histórico de lutas e conflitos e para a concepção do seu espaço de moradia optou-se pela interação do saber técnico e popular. Assim, vivenciou-se uma experiência repleta de conflitos, contradições e embates. Apesar disto, os condutores do processo sempre buscavam chegar, intuitivamente, a um consenso. Isso foi possível, sobretudo, na concepção da proposta. Mas, no preparativo para a construção, houve um rompimento com as propostas até então desenvolvidas. $O$ processo perdeu 0 sentido inicial, o qual tinha sido planejado e estava-se trabalhando.

Como lição, os detentores do conhecimento técnico devem buscar compreender o processo no contexto como um todo. Em alguns momentos, devem saber recuar em suas propostas, aceitar o que o outro sugere. Entender os momentos de ruptura, de dominação, de disciplina e tirar partido deles.

\section{Referências}

BORGES, Amadja Henrique. MST - Habitats em Movimento: tipologias dos habitats dos assentamentos originários do MST nos estados de SP e RN. São Paulo. 2002.Tese (Doutorado) - FAU/USP, 2002;

BOURDIEU, Pierre. Coisas Ditas. São Paulo: $1^{\underline{a}}$ ed. Brasiliense, 2004.

DEL RIO, Vicente. Introdução ao desenho urbano no processo de planejamento. São Paulo: Pini, 1990.

FERNANDES, Bernardo Mançano. Questão Agrária, Pesquisa e MST. Cortez, São Paulo: Cortez, 2000.

FOUCAULT, Michel. Vigiar e Punir: nascimento da prisão. Petrópolis: Vozes, 1987. 